\title{
Lusioersily
}

\section{The Emotional Nature of Birth Family Relationships for Care-experienced and Adopted Young People: A Longitudinal Perspective}

Fargas Malet, M., \& Mc Sherry, D. (2021). The Emotional Nature of Birth Family Relationships for Careexperienced and Adopted Young People: A Longitudinal Perspective. Journal of Family Issues, 42(10), 22632288. https://doi.org/10.1177/0192513X20978439

Link to publication record in Ulster University Research Portal

Published in:

Journal of Family Issues

Publication Status:

Published (in print/issue): 01/10/2021

DOI:

10.1177/0192513X20978439

Document Version

Publisher's PDF, also known as Version of record

\section{General rights}

Copyright for the publications made accessible via Ulster University's Research Portal is retained by the author(s) and / or other copyright owners and it is a condition of accessing these publications that users recognise and abide by the legal requirements associated with these rights.

\section{Take down policy}

The Research Portal is Ulster University's institutional repository that provides access to Ulster's research outputs. Every effort has been made to ensure that content in the Research Portal does not infringe any person's rights, or applicable UK laws. If you discover content in the Research Portal that you believe breaches copyright or violates any law, please contact pure-support@ulster.ac.uk. 


\title{
The Emotional Nature of Birth Family Relationships for Care-experienced and Adopted Young People: A Longitudinal Perspective
}

\section{Montserrat Fargas-Malet' and Dominic McSherry ${ }^{2}$}

\begin{abstract}
Research focused on relationships and contact with birth family for children and young people who were separated from them as infants has rarely acknowledged the emotional and dynamic nature of such interactions. Curiosity has been dominant in adoption research. However, in our longitudinal study of young people who entered care at a young age, a range of other feelings and combination of feelings emerged in the youths' narratives, including contentment and mixed feelings such as anger, affection, loss, guilt, or worry. Type of placement, that is, whether the young people had been adopted, lived with kinship foster carers or non-relative foster parents, did not determine their emotional reactions to their birth family. The young people's perspectives and emotions often changed over time. In this article, we describe the young people's emotional responses to birth family, and highlight implications for theory, research, and practice.
\end{abstract}

\footnotetext{
'School of Social Sciences, Education and Social Work, Queen's University Belfast, Belfast, UK ${ }^{2}$ School of Psychology, Ulster University, Coleraine, Londonderry, UK
}

\section{Corresponding Author:}

Montserrat Fargas-Malet, School of Social Sciences, Education and Social Work, Queen's University Belfast, 6 College Park, Belfast BT7 ILP, UK.

Email: m.fargas@qub.ac.uk 


\section{Keywords}

emotions, birth family, family relationships, care-experienced young people, longitudinal research

\section{Introduction}

The concept of family is contested and has changed over the years, as families come in all different shapes and sizes. We attach emotional meanings to family and family relationships. Emotions can work to undermine as well as to strengthen family interactions/sense of belonging to a family. For young people who have been separated from their birth family at a young age, the emotional meanings that they attach to family relationships and sense of belonging can be particularly complex, contradictory, and erratic. Much of the research on these young people has focused on the issue of contact with birth family but has largely neglected the emotional and dynamic nature of birth family relationships. This article reports findings from an ongoing longitudinal study of young people who entered care as infants in Northern Ireland. It focuses on how young people's understandings of, and relationships with, their birth family evolved over the years, as well as on the emotional responses and meanings they ascribed to them.

\section{The Research Context: The Childcare System and Birth Family Contact}

Within the United Kingdom, when children are found to be experiencing or at risk of significant harm as a result of abuse or neglect, Social Services will remove them from the care of their birth parents, and find an alternative home for them to be placed, initially on a short-term basis until legal processes can be concluded (McSherry \& Fargas-Malet, 2018). Most of the children who are removed eventually return to their birth parents (Sinclair et al., 2007). However, some children are not considered able to return to the care of their birth parents and, in those circumstances, alternative long-term placement options need to be sought. These options include long-term foster and kinship foster care; residential care (primarily for teenagers); care under private law Orders (i.e., a Special Guardianship Order or a Residence Order); and adoption. In the UK, adoption can occur without birth parents' consent, if consent is deemed to be withheld unreasonably, and this is the case in approximately $70 \%$ of adoptions (Kelly \& McSherry, 2002). In Northern Ireland, kinship and non-kinship foster carers can apply to have the Care Order superseded by a Residence Order (Children Order 1995, Article 8), which takes the child out of 
the care system and gives the carers shared parental responsibility with the birth parents.

Regardless of out-of-home placement type, in the United Kingdom and other developed countries, contact with birth families is regarded as vital for children's wellbeing and sense of identity. This idea has been promoted and endorsed internationally by the United Nations Convention on the Rights of the Child 1989, which specifies the right of children to live with their parents or keep contact with them when this is not possible. There has been a plethora of research on the benefits and pitfalls of contact for children in care and post-adoption contact (for a recent systematic review, see Boyle, 2017). However, there has been a lack of longitudinal research focusing on young people's understanding of birth family and the emotional nature of these relationships.

\section{Meanings of "Family" in Research with Care- experienced Young People}

Contemporary research on the family has highlighted significant transformations in family composition, with households becoming extremely diverse, and family boundaries becoming more flexible. These changes have affected the way young people ascribe meaning to family (e.g., Parker \& Mayock, 2019). These changes in family composition have also led to a move away from normative definitions of "the family" towards notions of kinship and a recognition of the dynamic nature of family relationships (Boddy, 2019). In this sense, Morgan (2011)'s concept of "family practices" is intended to "go beyond" certain models of family living, by emphasizing the idea of "doing family" rather than "being" a family. Thus, the focus is on gaining a better understanding of how individuals "do" family and the meanings they attach to their family practices. Finch (2007) added to this approach by recognizing the importance of "displaying" as well as "doing" family. She defined display as the practice of conveying to others and oneself that one's actions are indeed "family practices" and that these relationships are actually "family" relationships as distinct from other forms of relationship.

The concepts of "family practices" and "family displays" incorporate the notions of fluidity, diversity, and multi-facetedness that characterize family life (Finch, 2007). These two concepts have been widely used in research concerning children and young people in care or care experienced (Boddy, 2019; Holland \& Crowley, 2013; Skoglund et al., 2019) and adopted children and young people (Jones \& Hackett, 2011; MacDonald, 2017). For instance, in a qualitative longitudinal study of care leavers, 
Boddy (2019) found ordinary accounts of habitual family practices and highlighted the importance of young people's family relationships in understanding their sense of self, while in the study by Jones and Hackett's (2011), the complex meanings of everyday family practices, such as exchanging birthday and Christmas cards, were highlighted for adopted young people and their adoptive and birth families.

\section{The Emotional Dimension in Family Relationships}

Emotions play a fundamental part in all social phenomena, including the family. They are used to build social bonds as well as to stay committed to social structures or to tear them down (Turner, 2007), and in turn, our own social existence shapes our emotions (Jacobsen, 2019). However, there is no consensus on what constitutes an emotion, and a plethora of psychological (Cannon, 1927; James \& Lange, 1922; Lazarus \& Folkman, 1984; Schachter \& Singer, 1962) and sociological (e.g., Bericat, 2016; Turner, 2007) theories have been developed since the turn of the 20th century to try and understand this often elusive concept. Emotions have been defined in multiple ways, as they are highly complex and sometimes even paradoxical. Bericat (2016, p. 493) states that "emotions constitute the bodily manifestation of the importance that an event in the natural or social world has for a subject". Although this definition appears focused on the individual, it is acknowledged that emotions are in fact relational, as they occur, are felt, and have significance in the context of our social relations. In addition, we need to bear in mind that our emotional lives are dynamic in nature, and that emotions are never isolated or remain static over time.

The emotional dimension and significance of family practices and family relationships has often been overlooked in research focusing on disadvantaged families, and particularly in research looking at care experienced young people's understandings of their birth family. However, some authors, such as Wilson et al. (2012), stress the importance of exploring family practices in difficult circumstances, the resources underpinning these practices and their emotional significance. Their study focused on the family experiences of young people affected by parental substance use. Some of the participants had spent time in care. Emotional meanings of family were found to be connected to family practices. The young people in the study appeared to attempt to deal with, restore, and reset the boundaries of family. Holland and Crowley (2013), when drawing on findings from a qualitative study of care-experienced young people in Wales, highlighted the emotional co-presence of the birth family (i.e., being there emotionally/mentally, despite not always seeing them faceto-face) for young people living in substitute care, and the dynamic nature of experiences and perceptions of family relationships through the life course. 
In Kyrgyzstan, Sanghera et al. (2012) examined the emotions children and young people displayed when they were separated from their birth parents to be cared for by informal kinship carers and then re-united with their birth parents in adolescence. Their research showed the importance of emotional bonds with birth parents in affecting social relationships later in life. In their qualitative study focused on permanency and stability for young people in care, Moran et al. (2019) found that young people re-negotiated emotional bonds with their birth families, and emotions played a central part in understanding permanence and stability. In their study, some young people felt a sense of abandonment and anger towards birth parents, while others felt "torn" between birth parents and foster carers.

In this article, we report on some of the findings of a longitudinal study of young people who came into care when they were infants. In 2009, when the children were aged 9-14, we looked at the issue of contact with birth family (McSherry et al., 2013). In the current phase of the study, these same children are now young adults aged 18-24. From a longitudinal perspective, it was appropriate to continue to explore birth family relationships and their emotional significance.

\section{The Care Pathways and Outcomes Study}

The Care Pathways and Outcomes study is a longitudinal prospective study that has been tracking a population of children $(n=374)$ who were under the age of five and in care in Northern Ireland on the March 31, 2000. This is focused on understanding how the children and their parents and carers get on in the short, medium, and longer term, within and between the different types of placement group, that is, adoption, foster care, kinship foster care, Residence Order, and return to birth parents.

Three waves of the study have been completed to date. Wave 1 (children aged under 1-5 years) was focused on developing a baseline of demographics, background factors and reasons for entry to care for the full study population, with data extracted from social work case files. Wave 2 (children aged 3-8 years) tracked the placement profile for the full study population, in addition to interviewing a sub-group of birth, adoptive and foster parents $(n=$ 110), using both quantitative and qualitative methods, to understand how they and the children were getting on across a range of psycho-social domains (i.e., parenting stress levels and children's behavioral and emotional functioning) and broader issues such as experiences in school and relationships with family and friends. Wave 3 of the study (children aged 9-14 years) tracked the placement profile for the full study population at that time, and it included interviews with a sub-group of children/young people and their 
parents/carers $(n=72)$. These interviews again applied both quantitative and qualitative methodology and focused on a fuller range of psycho-social domains (i.e., parenting stress, children's emotional and behavioral functioning, children's attachments, children's self-concept, and children scholastic aptitude), in addition to broader issues such as school and peer and family relationships. Findings from these first three waves have been reported elsewhere (McSherry et al., 2010; 2013; 2016).

Wave 4 of the study (children aged 17-25 years old) is ongoing. To date, the placement profile for the full study population has been tracked (McSherry \& Fargas-Malet, 2018) and interviews have been completed, using both quantitative and qualitative methodology, with a sub-group of young people and their parents and carers. These have focused on a range of psycho-social domains (i.e., stress, attachment, self-concept, belonging, social support, self-control, and behavioral and emotional functioning), and wider issues such as education, training and employment, sense of belonging, key relationships, key events, and physical, emotional and sexual health. This paper focuses on young people's perspectives on relationships with birth family members gathered during Waves 3 and 4 of the study.

\section{Method}

\section{Design}

This is a prospective longitudinal study that is employing a mixed-methods approach to exploring the perspectives of young people and their parents/ carers on their lives, both quantitatively and qualitatively, across a range of psycho-social domains.

\section{Participants}

The sample for Wave 4 of the study is the same population of children that has been tracked in the previous three waves. In the current wave, a placement profile for $96 \%(n=354)$ of the study population was developed on the basis of placement data provided by Health and Social Care (HSC) Trusts in Northern Ireland (equivalent to local authorities in England and Wales), through to March 31, 2016. At that stage, 63\% $(n=259)$ were of 18 years or older, with $27 \%$ ( $n=95$ ) under 18 (either 16 or 17 years old). The findings from Stage 1 of the study have been published elsewhere (McSherry \& Fargas-Malet, 2018). In addition, semi-structured interviews are currently being conducted with the young people and their parents and carers, examining a range of issues. 
This article is focused on the semi-structured interview data collected from the 41 young people who have taken part in interviews to date. For 38 of them, their parents or carers have also been interviewed, but this article focuses exclusively on the young people's interviews. The interview schedule was structured around a range of issues, already specified in the previous section. Thirty-six of them had taken part in the previous wave of the study (Wave 3), when they were between 9 and 14 years of age. In that phase, some of these same themes had been explored, including contact with birth family and key people in their lives. Regarding placement type, 14 had been adopted as infants, 8 had lived in long-term foster care, 5 had been in long-term kinship care, 12 had been subject to a Residence Order (with foster carers), and 2 had lived with their birth parents for most of their lives. They were aged between 18 and 23 years at the time of interview in Wave 4.

\section{Data Analysis}

All interviews were audio-recorded and transcribed verbatim, and then analyzed using thematic analysis (Braun \& Clarke, 2006). We searched for recurring themes in the transcriptions from Wave 3 and Wave 4, and identified and developed detailed codes, which were input in Excel sheets. Each sheet referred to a particular theme (i.e., education, health, etc.). For this article, we specifically looked at the sheet on contact and relationship with the birth family. Within each sheet, the rows represented the young person across the two waves and their family, and each column represented a code, such as child's level of closeness to birth family in Wave 3, and young person's feelings towards birth family in Wave 4. Two researchers from the study read the transcripts and discussed the codes. All the names provided in the results section, and those within quotations, are not the young people's or other people's real names but pseudonyms assigned by the research team, so confidentiality is assured.

\section{Findings}

Young people's understandings and emotional responses towards their birth families were varied, dynamic, often complex and contradictory, and appeared to depend on a variety of factors, including their past and present interactions with individual family members; past experiences and memories; and the personal and social resources available to them. We identified four different categories, which are not mutually exclusive, as the young people in the study often fell into more than one of these groups depending on their relationships with specific family members, and they also shifted as they grew 
older. The categories identified in the analysis include curiosity; indifference or lack of interest; contentment/satisfaction; and ambivalence or mixed troubled feelings (i.e., a combination of emotions, such as anger, guilt, sadness, shame, grief, and worry).

\section{Curiosity}

Emotions can be a driving force for social action (Svašek, 2008). This is particularly intrinsic to the feeling of curiosity, as it motivates information-seeking and exploratory behaviors. Curiosity is very much linked to the feeling of uncertainty and being deprived of key information. For the young people, curiosity was also deeply linked to feelings of loss. Therefore, young people who lacked information about their birth families, or/and had never seen them or not seen them in a long time, often expressed curiosity. They felt a desire for information. These young people took action to satisfy this desire, including searching for birth relatives in social media, contacting them indirectly, arranging to meet them, or even going to live with them. The time when they remembered their curiosity surfacing (or acted on their curiosity) was often in their mid or late teenage years.

Curiosity has been a widely explored concept within adoption research (e.g., Jones \& Hackett, 2011; Wrobel \& Grotevant, 2019), and some of the young people who expressed being curious in our study were indeed adopted, probably because they were more likely to have been given less information and had less direct contact with their birth families. Family resemblance is a way to show biological connections (Mason, 2008, cited in Welch, 2018), and it was a source of curiosity for Julie. She first searched for her birth father on Facebook when she was about 14 or 15, and then she searched for her birth mother. However, she did not find her search particularly satisfactory:

I think more whenever it comes to my looks, I think I wanted more to see [my birth mum] because I wanted to see. . . I looked at him [birth dad] and I was "I don't look like him," so I was like "I want to find her because I want to see do I look like her then," and I think it was more the curiosity of like looking like your family that's where it came from. Because I like the way K and L [adoptive sisters] can go "oh you've got mummy's" and "You've got daddy's," but it's like a small thing. But then I was like "I wonder where I get mine from." I don't think it was about them, but I think it was more a selfish thing, where I wanted to know what I look like, why I look like that. And then I got nothing from it because I still don't think I look like them.

For other young people, their curiosity brought them to want to make contact with their birth parents. Not all the young people who felt this way were 
adopted. Janette, who lived with a foster family since the age of two, had contact with her birth parents at the start of the placement, but contact with her mother lasted for six months and contact with her father also stopped shortly after. She felt the desire to get some answers from her birth mother. However, as Greenhow et al. (2016) found in their study of traditional and technological forms of post-adoption contact, "out of the blue" virtual contact, without prior managed contact, like the one Janette experienced, can be challenging, and she was not given any support to deal with it:

Well of course you search for them. Like I'm sure everybody does it. Yes, I've done it. I have searched for my mum and my dad. I actually found my mum in Facebook and it was the worst mistake I've done in my life. Because I did speak to her and of course I had to ask her what I needed to know. And it just turned out to be. . . Like she was really rude and [. . .] So I blocked her and. . . I haven't went looking for her anymore 'cause I know why did I need to do that? [. . .] I think I just needed to know. I needed to ask her "does she ever think of any of us?" like "does she ever regret what she'd done?," well, it wasn't really her choice anyway so ... I think I was just more annoyed at the fact the way she got on, but I haven't been looking for her ever since.

Some adopted young people also made contact with their birth parents, but, in their case, they knew they had to wait until the age of 18 to do so. Brendan never had any contact with his birth family during his childhood years. When he turned 16 or 17 , he started searching for information on his birth family. He eventually did find his mother, who lived in a neighboring country, and he made contact with her. He told his adoptive parents after he had found her, and subsequently his birth mother booked flight tickets for him to go and meet her. He did not regret his decision to search for his birth mother. $\mathrm{He}$ regarded it as something that he had to do. When asked why he searched, he answered:

. . curiosity, being nosy probably is another one. You know, at the end, it's things that everyone should know, and should want to know as well. [. . .] I was definitely glad I did do it. It was a bit of a hard time, but I was definitely glad I'd done it. I think if I didn't do it, then you know, I would still be sitting here probably regretting not doing it.

For two other young people in our study, their wish and longing for one day meeting their birth parents was crushed, and they were left with feelings of loss and grief, after finding out their birth mothers had died before they turned 18. Olivia remembered faintly that she used to see her birth mother once a week when being fostered in the early years of her life. Contact stopped, and 
she was then adopted. She continued having post-box contact with her birth father (i.e., he sent letters/cards to her at birthdays and Christmas) throughout her childhood. When she was interviewed at age 10, she expressed curiosity regarding her birth parents, and included them both as part of her family. She considered them as very close to her, despite not seeing either of them. She also told us that she would go and see her birth parents when she was older. She expressed sadness about her past because she did not get to stay with her birth mother. She said that it bothered her that she did not know them. Olivia's birth mother passed away when she was 14 . In a more recent interview, she described this as one of the most challenging events in her life. Her account in the earlier interview substantially contributed to understanding her emotions in the current stage. However, she found herself unable to express her feelings of loss to anyone who she felt could really understand, as she did not know any other adopted youth. She also explained how she met her birth father when she turned 18, and described it as a positive experience:

Because no one does really understand, it's really hard to talk to someone directly because they can't connect to it. [. . .] It was really hard because obviously like I never blamed her for any of it. And obviously a part of me, because I wasn't allowed to see her until I was 18, and a part of me always wanted to. And the realization of not was hard. But . . I met my dad there a while, just before Christmas. So it was weird but it was good.. . . We exchanged emails but . . . obviously with me being on my course, I didn't want to . . . I just said I would be in contact over summer if he would be willing to meet again. That was it.

Others, like Niamh, who grew up with her paternal grandfather and birth brothers, also wanted to find out more about birth relatives and maybe even contact them. However, despite not being deceased, other circumstances prevented them from doing so. In her interview in 2009, Niamh said that she considered her father to be part of her family, although she had not seen him for many years. She also thought of her birth mother as being part of her "distance family" despite not seeing her either. For her, the emotional significance of her birth parents appeared to endure until early adulthood. Niamh had found her father in Facebook and discovered that he had started a new family. Her father had sent her letters throughout her childhood, but a few years previously, he asked her to meet with her alone, excluding her brothers (i.e., his two sons). She felt that this would have been wrong and unfair to her birth brothers, so she never went ahead. She never found her mother either, but talked about her desire to do so:

Untraceable. She doesn't want contact. And I'd like to know her. I would actually really love to know her because you know, sort of not having really much of a mother figure in your life, it's sort of . . . and I'm always really 
curious to sort of . . because I obviously have half your genes, half of my genes are yours, so ... I'm curious.

Other young people in a range of placements (adopted, in foster care and subject of Residence Order) took their actions further by going to live with their birth parents. Similar to other studies (Wilson et al., 2012), their accounts often reflected the power of actual and idealized ties to birth families, as they made eager attempts to rebuild relationships with parents, despite current or past difficulties. For William, who was adopted, this experience turned out to be rather challenging, and his conception of his birth family, as well as his interactions with them, changed as a result of it.

Curiosity mainly drove it. Just to see . . . what it was like.. . . It just happened. I can't even describe how it happened because it happened so quickly. [. . .] [My birth mum] had repeat alcohol abuse. She said she was clean for so many years, but she was still going back to it. I didn't know about this, but she had a younger son, who was 14,15 at the time.. . . We got on at the start. But the way I see it is that he was putting on an act and then he started to show his true colors and then it was just worse, worse, worse. [. . . I had to call the police to get myself removed. It was that bad. [. . .] there was social workers for the younger brother involved then. So they'd arrived, she was nowhere to be found. . I rang, she said, "Right, leave it. Just tell her to go away." She couldn't go away. I rang again and she goes just "blip, blip, blip," and I goes "right, get back here no," and she came back and all hell broke loose basically.

Similarly, Rose went to live with her birth father when she turned 18 for a brief period. She had grown up with foster carers, who obtained a Residence Order for her. She had contact with her birth parents, but when she was four and a half, there was an incident with her birth mother, who had been drinking and set the house on fire, and the birth father became violent. When we interviewed Rose at the age of 12 , she told us that her parents scared her, and recalled this incident. In contrast, when we interviewed her recently as a young adult, she included her birth mother as part of her family, although she had died 6 years previously. Regarding her recent experience of moving in with her birth father, Rose recalled how it turned out to be unsatisfactory:

And then we started like building a bond, but ever since it is gone. Because I thought building a bond after all those years would have worked but no, he didn't really care, because he was coming in, walking straight past me.

When asked why she wanted to build a bond with her father, her answer revealed an idealized notion of birth family ties, which collapsed after her experience: 
Because he's my dad at the end of the day. That's how I see it. But in a way, because of everything that has happened in the past and the way he's been getting on me, I don't really want to build a bond anymore. I would rather keep it the way it is.

To sum up, while discovering new information is usually rewarding and a positive experience helping reduce the state of uncertainty, some of these youths experienced searching for and initiating contact with their birth families as difficult and often distressing. Sometimes, as a result of these experiences, the meaning and emotional content these young people had ascribed to their family relationships drastically changed. However, despite being challenging, some also considered these experiences as positive and were glad they had endured them. These narratives also showed the powerful "emotional co-presence" of birth family members, being there emotionally/psychologically in the young people's lives, despite them not always being there physically (Holland \& Crowley, 2013; Skoglund et al., 2019).

\section{Indifference or Lack of Interest}

On the other side of the curiosity spectrum, some young people expressed a lack of interest or indifference towards their birth family. This group of young people was heterogeneous. Thus, not all of them had arrived at this standpoint in the same way. While some young people had always felt like their birth families were not relevant in their lives and had no interest in them, other young people had displayed other emotions previously, but as a result of past experiences, had become indifferent.

The group of young people who had never felt an interest towards their birth family or specific members of the birth family included adoptees, young people who had been subject of a Residence Order taken by relatives and non-relatives, and young people who lived in kinship care. These young people had never considered these birth relatives to be part of their families, and they hardly had any contact with them. They all felt settled within the family they grew up in from a young age. Fionn, adopted as a baby, did not have face-to-face contact with any members of his birth family. His adoptive parents gave him most of the information they had about the birth family, and they shared with him letters and photographs. When he was interviewed at the age of nine, he said that he had never seen his birth parents, but he had pictures of them, and he preferred being in the family he was now. In this current phase, he made clear that he had never met them and had no intention to meet them either: 
I have never seen them.. . . I have never really thought about it. [. . .] knowing about your past and birth parents isn't important to everyone.. . .

Mark and Jeremy were not interested in their birth fathers, and when they died, neither of them went to their funeral. Mark, who was living with his foster mother (that took a Residence Order), was particularly critical of his birth father's lifestyle, and his death did not have much an impact on him:

Probably because he was never there, you know.. . . I didn't know him enough.. . . They phoned [my foster mother] to ask to see if I wanted to go but ... I said "No" because there is no point in going.

Similarly, Jeremy was never interested in his father. Jeremy lived with his maternal grandmother since he was very young after his birth mother had died. He had never seen his father, as he lived in a neighboring country. According to his grandmother, he refused to go to the funeral, and Jeremy's account reflects this lack of emotion towards him:

No, he's dead. Aye, he died, I never met him. He died about five years ago maybe, I don't even know, I don't care. I've seen his picture.

Sometimes, young people had expressed mostly painful feelings about birth relatives in the past, which had turned into indifference as they grew older. This second group was also diverse regarding care histories. Madeleine, who was adopted together with her birth brothers, never considered her birth mother to be part of her family. When she was interviewed in 2009, she expressed anger and sadness about her past, and felt a sense of abandonment from her birth parents. She used to have contact with her birth parents in the adoptive family home, but it stopped after her birth father was killed when she was about five, and her birth mother failed to turn up to visits after his death. In the current phase of the study, when she was interviewed again as a young adult, Madeleine's feelings of sadness and anger had dispelled, and instead, she claimed she was no longer interested in her:

I know about her and that and I would know her to see her and that there, and I'm not even interested, she's not interested like. I was in [town shop] last Saturday and she was there with her boyfriend, she's just. [. . .] No, probably [doesn't recognize me] like I've changed a while lot, but I'm not interested.. . .

In contrast to Madeleine, Killian had regular contact with his birth parents and siblings throughout childhood. Killian grew up with a foster family, who took a Residence Order for him. As a young child, he considered his birth 
family as part of his family, but he did not feel very close to them. As a young adult, his feelings had shifted, and he did not consider them as part of his family anymore. He had not visited them for some years. He stopped visiting them after his mother started drinking again. In addition, his birth family became confrontational when he changed his name:

There was a period there where she never drank- and I sort of thought right you've grown up now so I will come up and see you. So I went up and everything was alright and then went back up a week after and it was absolutely hectic with the drinking it was just . . . all the situations were going on at once. So I sort of thought to myself right I'll take myself out of this. [ . . . ] that sort of kicked up a whole fuss just about getting my name changed and I just thought, "You know what? if you are going to be that childish rather than just dragging it on for this long, then just don't talk to me." [ . . .] So that's whenever I did sort of stop talking to them. They did ask me to come up and they did try to get in contact with me but I wouldn't.

James also had contact with his birth parents throughout most of his childhood growing up in foster care, but he expressed indifference towards his birth family as a young adult. When we interviewed him at the age of 13, he felt sad about his past, and wished his parents would "stop drinking". He worried about it before having contact visits with them, and whether they would turn up or not. As a young adult, James remembered his parents failing to turn up for contact visits and the impact that had in his emotional wellbeing:

I just knew I wasn't with my mummy and daddy. But now I don't even care about that. I don't even bother with themuns, I couldn't care. . . most of the times they wouldn't show up and then that there messed my head up even more.

However, despite him claiming not to care anymore, he did express anger and frustration towards them. His emotional response appeared greatly connected to his parents' breach of what he considered as fundamental obligations to him, that is, giving up drinking and turning up to see him:

And from that there moment, it made me go mad.. . . You just sit and think about it. Do you see now when I am in bed, I still just think about it.. . . I said to my mummy and daddy and all like. I said to them "you f*cked my head up." They don't see themselves as having done anything wrong.. . . They are still drinking like. Well my dad is in jail now. She was given a choice, to drink or kids? And they picked drink, so. . . 
Brandon had also felt rejection from his birth family as a young child, which had affected his emotional wellbeing to a point where, as a young adult, he claimed that he felt nothing for his birth mother and had no relationship with her. When interviewed during the previous wave of the study as a 14-year old, he did not consider his birth parents to be in his family, but he considered his older brothers to be. As a young adult, Brandon explained how his mother kept one of his siblings, but she left him in state care, and how this had emotionally wounded him:

Up until seven, I would have been in a few homes with one of my brothers. And then our mother took him home and left me in the system. I think that was a big thing. I got really bad after that happened. So from about seven to ten when that happened, and then I was sent to more homes, I think I just gave up then. So, I had to protect me at a young age and stuff. [. . .] Something happened at around ten. I'd met my mother, and I talked to her. And we had a talk and she basically disowned me there and then that day. Yeah, and she just said never come home, and that she didn't care about me and stuff like that.. . . I think that was the make-up of me that day, and then after that, I just didn't have any emotions or any. . .

To sum up, young people who expressed a lack of interest towards their birth family or particular family members often had a strong sense of belonging to their alternative family (whether foster, adoptive, Residence Order, or kinship), and no longer felt (or had never felt) that their birth families were part of their family. This was especially exhibited in family displays (Finch, 2007), such as Killian changing his own surname. While some of these young people had never felt in any other way, others had felt some emotion towards their birth family previously, such as sadness, a sense of abandonment and anger. For a few like James, some of these feelings persisted in some way.

\section{Ambivalence or Mixed Troubled Feelings}

Ambivalence has been regarded as a "mixed emotion" comprising mutually contradictory feelings towards the same individual/object (Weigert, 1991, cited by Jacobsen [2019] and Finn [2013]). Some young people struggled with complex and contradictory feelings towards family members. For most of these young people, relationships appeared problematic. As previously noted in narratives like Brandon's, they often recounted stories of rejection and abandonment, which led to feelings of anger, resentment, hurt, and loss. When interviewed for Wave 4 of the study, Nichole talked about these 
troubling feelings towards his birth father. She had lived with a foster family since she was a baby, and they had taken a Residence Order on her. As a child, she used to go to see her birth parents regularly, but that stopped when she was quite young. During the interview, she recalled her earliest memory, which was going to see her birth father when she was about five and him not turning up. At present, while she was still in touch with some birth family members, her relationship with her father remained inconsistent and challenging, often involving social media difficulties:

\begin{abstract}
My dad added me on Facebook when I was 16. And then a few of his sisters added me and his ma and dad. I had a big fight and argument with my dad, I know that. I took a lot of anger out on him. It actually felt kind of good like but. . . . . .] Yeah, not really knowing anybody and then getting a load of messages "God we missed you," and all I am sitting like "you knew where I was and I don't even know you." I don't take well to that. [. . .] It is really hard to explain, mixed feelings, you don't know how you feel, and then you think about it and then that's when you start to get angry when you think about it. [. . . I talk to my auntie sometimes. She used to phone me like every day and now I just talk to her every other day. I talk to a few of my cousins. My dad, he will block me and then unblock me again on Facebook.
\end{abstract}

Anna also felt anger and resentment towards her birth mother, when the latter contacted her in her late teens, after a long period of absence. Anna grew up in foster care with one of her birth brothers. She had contact with her birth parents until she was about 13 or 14, although her parents often did not show up. When we interviewed her as a child aged 12, she expressed her wish for her parents to give up alcohol. When she became pregnant in her late teens, her birth mother approached her and showed interest for her expected grandson, and that fueled her anger. She also recalled an earlier incident where her mother did not recognize her:

I would have went to my sisters and stuff, and then there was one time that I went round to my mum's with my sister and she basically put her hand out and introduced herself and she said, "Hi I am [sister's] mum, nice to meet you." So I was just like, "Hi, I am Anna, your daughter," do you know that way? [I felt] rubbish yeah. I was just like, it is a disgrace. So I think like the more things are done, the more I just get angry about. And then once the child was born, she thought she was going to be Granny of the year, and she doesn't understand, she starts with me first, before she can start with my child. [. . .] As soon as I was pregnant. And she was in touch all lovey dovey and "I am going to get him this and that." But I just said to her, "At the end of the day, what about me? Not once in that conversation have you asked "how are you? Do you know that way?' 'Like I am your daughter'.” 
However, despite having these negative feelings, Anna also expressed her wish to understand her birth mother and the circumstances that led her to become looked after. That was her motivation in trying to obtain her files and doing some life story work. In her narrative, she appeared to have an internal debate with herself between what she felt (i.e., animosity) and what she thought she should feel (i.e., empathy, compassion):

But I think it will just be like, a thing for me because at the minute I just don't see my mummy as, like in my head I just don't like her but at the same time I have to understand that being an alcoholic is a disease as well, do you know what I mean? You know like it is an illness but I just need to understand the things why, so maybe one day I can forgive her, do you know that way? because if anything did happen to her, I would probably still be upset, you know that way? but I would still probably not even show up, do you know that way?, if anything did happen. I think I just need to find out so I can . . . for my own peace of mind.

Mia also struggled to understand how her birth mother did not change her self-harming lifestyle. Mia had lived with a foster family for most of her childhood subject to a Residence Order, but that relationship broke down when she was in her late teens. She had been seeing her birth parents regularly every three weeks, but contact stopped for about six or seven years when she was in secondary school. As a young adult, she claimed not to fully know why, as her mother "never tells me the full story." When we interviewed her as a child at the age of 12 , she had just started secondary school and had not seen her birth mother for a few months "because she had to settle into junior school." She told us then that she was going to see her soon, and that she enjoyed seeing her. As a young adult, she explained how she regained contact with her birth mother, and that she considered her birth family as her only family now, as she had no other family to fall back on. However, her relationship with her birth mother was not that supportive due to her mother's life-long addiction:

Oh, aye, I can go and talk to her whenever I want, but she's a full alcoholic now like. [. . . The three younger weeans that she had, she's lost them too.

Carl's narrative included a multiplicity of conflicting emotions towards his birth family, including love, dislike, and despair. Carl lived with his foster mother for many years. When he was in his early teens, he was displaying challenging behaviors and emotional difficulties caused by multiple bereavements. In the space of three years, his foster father, his birth brother, and his birth grandmother had died. In contrast to Mia, despite him leaving the foster 
family home when he was about 15 , his relationship with his foster mother persisted, and they were both still very much part of each other's lives. After leaving, he moved into a residential unit for a few weeks, and then went to live with his birth aunt for about 18 months. He then moved in with his birth mother, who had a long history of drug misuse. At that stage, he started abusing drugs with his birth family. He recently was able to stop his drug-taking and settle with his girlfriend and child. When asked why he was still visiting his birth family, his response exposed the powerful cultural ideal of the "normal family" (Wilson et al., 2012):

Because I wanted a proper family, I wanted a mum and dad like [my girlfriend's] ... I wanted a family that loved me and wanted to see me doing well... . I don't get that at all. I think I keep coming back to try and see if there is change.. . . But I want to see my mum get off tablets too, as much as I don't actually like her. I love her but I don't like her. I don't like her company. I'm probably wording this all wrong, but you know what I mean. [. . .] I feel responsible for my mum. I feel I have to mother my mum every time I am with her.. . . Yeah, worrying about her wellbeing.

Carl was struggling in his ambivalent position, whereby he was trying to protect his own wellbeing and lifestyle by distancing himself from family members, while at the same time, being pulled by his longing to have "a proper family" and his feelings of love, care and concern towards them. This ambivalence seemed to be the source of emotional difficulties, like "feeling low" and anxiety.

But I feel like . . because I work and none of them can't work, and I drive and none of them drive, you know, they always have something to say about every wee thing you do, and then it just feels that you always are joke of the jack with you . . . It's not nice, it's really not nice like. Every time I'm with them, I leave upset or feeling low, every time I see my mum, I have instant anxiety, instant anxiety, even talking about it. My heart is racing now, even talking about it. I swear to God, I can't deal with her.

Sibling relationships were very important for many young people in the study. However, for a few participants, brothers and sisters turned out to be the source of very complex emotions and challenging relationships. Eric's mental health was negatively impacted when he found his birth sisters when he turned 18. Eric was adopted at a young age by the family who had fostered him as a baby. When interviewed during the previous wave of the study at the age of 11, he expressed sadness about his past because he did not remember his birth mother. As a young adult, he told us how one of his birth sisters had 
recently disclosed negative stories about their birth mother and he had not been ready to listen to those:

Well, this year like I found out that I had two big sisters, that I had two big sisters. [...] And then it was sort of like, I got really depressed this year because of it. [. . .] one of my sisters put a load of crap on me because of, about the real family, which I didn't really want to know. It was affecting me, and I had it in my head. [. . . ] They aren't bad people, but they didn't really understand what I was going through at the time.

Julie also had complex relationships with her siblings. Julie, who was adopted, felt overwhelmed by her relationship with her birth sister. As a child, Julie used to see her brother and sister three times a year, when they did different activities (e.g., go bowling, cinema, etc.). When interviewed as a child, she considered them to be part of her family, but she did not feel in any way as close to them as she was with her adoptive sisters. As a young adult, Julie recalled how she stopped talking to her birth brother, because he went back to live with their birth mother. It also appeared that her birth sister was very eager to keep their relationship going, through family practices like exchanging cards and gifts. Julie and her sister appeared to have very different expectations and understandings of this relationship. This caused an emotional dilemma for Julie, who felt a mixture of emotions, including guilt, awkwardness, dread, and pity:

I would like to get to know her, but like slowly. I feel a bit guilty, I think, whenever I meet her. [Our brother] now walked out on her. She never had a mum or a dad. She fell out with her carers like. She has nothing. And then, I think I felt I would go and make an effort to see her. And then when I went to see her, I was like this is intense. I started to get like presents and cards that were like sister. It was quite scary. And then in her Facebook it was like . . my sister. And people were like, "Who is this person?"

To sum up, feelings of ambivalence were often not resolved. Most of these young people found it hard to come to terms with and make sense of their parents' behaviors and life situations. They craved the existence of what they considered a "normal family". However, these feelings were dealt with in different ways, including avoiding or ignoring challenging situations (e.g., visiting the birth family less or not at all) and even rejecting family members; confronting birth family members (like Nichole did with her birth father); and attempting to rationalize/understand or empathize with their birth family. Sometimes, these responses could lead to a certain harmony or to some degree of (internal or external) conflict (Connidis \& McMullin, 2002). 


\section{Satisfaction/Contentment}

Satisfaction is considered one of the primary emotions (Bericat, 2016). Satisfaction or contentment is also a positive event-related emotion. Most young people that expressed contentment with their birth family relationships had always had regular contact with their birth family. Some felt that their family comprised members from the birth family and from the adoptive/foster/kinship family, although many were much closer to one or the other of the families, and they did not see them as equivalent. Either way, young people appeared to have successfully negotiated loyalties and a sense of belonging between the birth family and the family they lived with, or either with one or the other. Gavin grew up in foster care, but he maintained frequent and regular contact with his birth mother and siblings. He felt part of both families:

Even now I have a healthy relationship with both families. [. . .] My mum is my mum, and she's always been there for me, but [foster mum] is always been there for me . . . so I consider both my mums.

Gavin's foster mother and birth mother had always enjoyed a positive relationship. When he was a teenager, he had an argument with his foster mum and went to live with his birth mother for a couple of weeks, but he explained that he felt sad, guilty, and remorseful, and his birth mother told him to go back and apologize, which he did. He continued to visit his birth mother and he did that now accompanied by his girlfriend. He felt love but also guilt and hopelessness due to the situation his mother was living in:

I would see my mum and see my brothers in a bad situation, and I wouldn't really be able to help, because I wouldn't be there all the time. I still do. My wee brothers are getting at that age, 15,16 , they are getting in trouble. And I can't really help them. [. . .] It is frustrating, because I know if I was there, it wouldn't be the case, because sometimes my mum can't really . . . it's hard for her. She's a single mum and with two boys at that age. . . it's hard to keep them on [. . .] Like she's a brilliant mum. She's fine now. My mum is brilliant now, but it's not her I'd worry about. It's the two boys, it's them causing her bother, and getting her into trouble.

In contrast to Gavin, Chloe did not feel anywhere near the same level of closeness with her birth mother as she did with her foster mother, despite being content with her relationship with her. Chloe went to live with her foster family with her older birth brother when she was only 14 months and he was about four or five years old. She contrasted her own feelings with those of her brother, who appeared to feel closer to the birth mum than she did: 
He [birth brother] would still keep a relationship with the birth mum and stuff like that, I have tried to keep a relationship with her. But to me, I know as horrible as it sounds, I just can't seem to get that, you know. My mum's my mum now, and that's what it is. While he would be quite. . he sees mum as mum now but. . . his birth mum and stuff he would still call her mum and go down to see her and. . . [. . ] He would be a lot closer to [obirth mum]. I wouldn't really have that relationship.

For young people in kinship care, there were often tension and conflict between kinship carers and birth parents. As in Welch (2018)'s study, kinship foster carers mentioned strains and difficulties in their relationships with the young person's parents. Some young people either chose to ignore these tensions in their narratives or minimized them despite being somewhat conscious of them. However, for others, family tensions created some level of emotional discomfort, which was pointed out during the interviews. Jim lived with his maternal grandfather and his wife, who took a Residence Order for him. Jim's birth mother is the daughter of the foster mother's husband from his first marriage. Throughout his life, Jim had regular contact with his birth parents and siblings, but it was not very frequent. Jim had always considered his birth parents as part of his family, but he felt his foster parents were the key people in his life. Recently, he explained how he barely went to see his birth parents in the past, just for Christmas and birthdays, but he visited them much more often now, especially his birth father. The birth parents had separated. He was also seeing his siblings more often. Although he indicated being satisfied with his relationship with his birth parents, and especially with his birth siblings, there had been situations that he found emotionally difficult in the past. For instance, the fact that he had always called his foster parents "mum" and "dad" had brought 'awkward' moments in his interactions with the birth parents, as he recalled:

There has been a few times were before they fell out with each other, it was a hard situation because you have to sort of think before you speak because you are that used to say to [foster mother] saying mum, but when my biological mum was here it was like [foster mother's name], and you just felt awkward, it didn't feel right calling her [foster mother's name]. You felt this obligation that you didn't want to hurt. . . but you used your own wee strategies to deal with it. [. . . Y Yeah, it is just finding my own way to deal with everything as best I can. Bottling it up was a big problem for a long time just keeping everything inside but I started opening up a good bit when I started going with [girlfriend] so ... Counselling as well.

For Sophie, her relationship with her birth father changed as a result of her moving out of her kinship carers' home. Her kinship carers, who were her 
maternal grand-aunt and grand-uncle, did not have a good relationship with her birth father. The relationship between the kinship carers and Sophie had broken down when she was 17 , when she moved into her own apartment. Sophie acknowledged her birth father's harmful behaviors and decisions but expressed empathy towards him and feelings of affection and emotional closeness. She had built a narrative making sense of his damaging behaviors. She also emphasized her more recent experiences of receiving practical and emotional support from him, through family practices and displays, such as decorating her flat or buying things for her.

I love him. He's amazing yeah.. . . I always loved him and all, but er. . . he would have never came. . well, he would have came sometimes, but the majority of times, he would have been the one to let me down, and my mummy would have been there. [. . .] whenever I moved in to here, my daddy was like. . . "I thank God! I can go to her now." Because he felt like he wasn't welcome, you know, and my aunt and uncle looked down on him and stuff and frowned upon him.. . . But as soon as I like moved into here, he like decorated this whole place for me, he bought me lots of stuff, and he's always been there for me, you know. I think he just didn't like the Social Services' side of it and he just couldn't deal with it, he didn't know what to do. And then, his drink problem too, it was just more important. And he just couldn't get away from it. But we are really close now compared to back when like I was living with my aunt and uncle. [. . .] And I am glad that I'm close with him because like why not? you know. . . he's not bad to me now, yes, he made some really shitty decisions and sometimes I look at him and go, "You really . . . like I don't even know if I know you because of the things you've done in your life, like you know I couldn't imagine doing," but it was his lifestyle and that's what he'd done and he has to live with that, you know, and he does.

Thus, even when young people were satisfied with their birth family relationships, they often held other feelings or had held other feelings towards them. In addition, not all of the young people in this group felt the same degree of closeness or sense of belonging. However, they had all seemed to work through their emotions towards their birth family members and the families they had lived with (i.e., adoptive, foster, or kinship families).

\section{Discussion}

Two main study findings were uncovered in this article. First, regardless of placement history (i.e., whether they were adopted, had been raised in longterm foster care, kinship care, etc.), care-experienced children and young people's relationships with their birth family have a clear emotional 
dimension. Indeed, the emotional meanings attached to family can be extremely complex for young people who have been separated from their birth parents at a very early age. In this study, young participants expressed a variety of emotions towards birth family members, which included curiosity, indifference, mixed and complex feelings (e.g., anger, concern, pity, sadness, guilt, etc.), and contentment. These emotions were often revealed through family practices (e.g., attending/not attending family rituals such as weddings or funerals) and family displays (e.g., changing their family name). As in Holland and Crowley's (2013) study, we found evidence of the powerful co-presence of the birth family in the emotional world of many of the participants in the study, despite most having not seen them from a very young age. In addition, several appeared simply unable to escape relationships with birth family, despite these being frequently challenging or difficult (Skoglund et al., 2019).

As argued by Wilson et al. (2012), emotional encounters are shaped by direct social interaction, memories, imagination, expectations, and aspirations. In other words, our social existence, including social, structural, and cultural forces, shape our emotions (Jacobsen, 2019). In this study, some indication was found that young people's past experiences, memories and interactions with the birth family and the foster/adoptive family, their aspirations and expectations, and their current life situation (in terms of social support, socio-economic status, and resources) shaped the emotions they had towards their birth family. However, the emotions shown by these young people did not appear to depend on the young person's placement type. For example, for some participants in the study, their curiosity was partly product of their knowledge gaps in relation to their birth family and/ or the quality of communication they had with their adoptive/foster family, more so than whether they had been adopted or been placed in long-term foster care. For others, their ambivalence/complex feelings or their indifference was partly due to past encounters and interactions, or/and birth family members not conforming to their idealized versions of parenthood. Indeed, some young people's accounts reflected the influence of idealized notions of the nuclear family and a concern for the quality of these relationships (Wilson et al., 2012).

Second, children and young people's emotions towards birth family were not static but changed over time. Emotions were fluid and shifted depending on the changes and transitions in the young people's own lives and new experiences. Because of the longitudinal nature of this study, we were able to reveal this dynamic and fluctuating character of family relationships and the young people's emotions towards individual family members (Skoglund et al., 2019). Thus, some young people who had previously felt curiosity 
towards their birth family did become angry or disaffected as a result of their experiences of contact and interactions with them; while others who had previously felt anger and feelings of loss towards birth family members had become indifferent; and some who were curious in the past were currently satisfied with their relationships with specific family members.

The study raises implications for clinical and social work practice, as the emotionally dynamic aspect of contact with birth family in out-of-home care has been largely ignored. As it has already been highlighted in other research, it is important that care-experienced children and young people (regardless of their care histories and types of placement, i.e., adoption, foster care, etc.) should be given information on their birth family, and their views on the level of contact should be sought and constantly reviewed. Thus, for example, adopted young people who might want to meet their birth parents should not be forced to wait until they are 18, if there are no compelling reasons to do so. On the other hand, young people should not feel coerced to have relationships that do not wish to have or that are emotionally harmful for them, or to have conversations that they are not ready to have. Some will need help to deal with negative, conflicting, and confusing emotions emanating from their experiences of searching, making contact, and losing family members. Thus, it is important that children and young people are and feel emotionally supported in their relationships with birth family members throughout their lives, as these are likely to change with time.

To sum up, this study makes a case for recognizing the emotional significance of young people's relationships with their birth families throughout their lives. We should avoid the binary view of birth family as either "good" or "bad" (Boddy, 2019; Finn, 2014); and be mindful that young people's experiences and feelings are all different, and they need to make their own decisions, but have the appropriate support and guidance around them to do so.

\section{Declaration of Conflicting Interests}

The author(s) declared no potential conflicts of interest with respect to the research, authorship, and/or publication of this article.

\section{Ethical Approval}

Ethical approval for the study was granted by the Office of Research Ethics Committees in Northern Ireland (ORECNI).

\section{Funding}

The author(s) disclosed receipt of the following financial support for the research, authorship, and/or publication of this article: A grant to fund Wave 4 of the study was provided by the Economic and Social Research Council (ESRC) in the UK. 


\section{ORCID iD}

Montserrat Fargas-Malet (iD https://orcid.org/0000-0002-1154-3321

\section{References}

Bericat, E. (2016). The sociology of emotions: Four decades of progress. Current Sociology, 64(3), 491-513.

Boddy, J. (2019). Troubling meanings of "family" for young people who have been in care: From policy to lived experience. Journal of Family Issues, 40(16), 22392263.

Boyle, C. (2017). "What is the impact of birth family contact on children in adoption and long-term foster care?" A systematic review. Child \& Family Social Work, $22,22-33$.

Braun, V., \& Clarke, V. (2006). Using thematic analysis in psychology. Qualitative Research in Psychology, 3(2), 77-101.

Cannon, W. B. (1927). The James-Lange theory of emotions: A critical examination and an alternative theory. The American Journal of Psychology, 39, 106-124.

Connidis, I. A., \& McMullin, J. A. (2002). Sociological ambivalence and family ties: A critical perspective. Journal of Marriage and Family, 64(3), 558-567.

Finch, J. (2007). Displaying families. Sociology, 41(1), 65-81.

Finn, K. (2014). "I just never thought he'd be that way": Young women, higher education and the shifting emotional dimensions of home. Families, Relationships and Societies, 3(1), 35-50.

Greenhow, S., Hackett, S., Jones, C., \& Meins, E. (2016). The maintenance of traditional and technological forms of post-adoption contact. Child Abuse Review, 25(5), 373-385.

Holland, S., \& Crowley, A. (2013). Looked-after children and their birth families: Using sociology to explore changing relationships, hidden histories and nomadic childhoods. Child \& Family Social Work, 18(1), 57-66.

Jacobsen, M. H. (2019). Liquid-modern emotions: Exploring Zygmunt Bauman's contribution to the sociology of emotions. Emotions and Society, 1(1), 99-116.

James, W., \& Lange, C. G. (1922). The emotions. Williams \& Wilkins Co.

Jones, C., \& Hackett, S. (2011). The role of "family practices" and "displays of family" in the creation of adoptive kinship. British Journal of Social Work, 41(1), 40-56.

Kelly, G., \& McSherry, D. (2002). Adoption from care in Northern Ireland: Problems in the process. Child \& Family Social Work, 7, 22-24.

Lazarus, R., \& Folkman, S. (1984). Stress, appraisal and coping. Springer.

MacDonald, M. (2017). "A picture of who we are as a family": Conceptualizing postadoption contact as practices of family display. Child \& Family Social Work, 22, 34-43.

McSherry, D., \& Fargas-Malet, M. (2018). The extent of stability and relational permanence achieved for young children in care in Northern Ireland. Children Australia, 43(2), 124. 
McSherry, D., Fargas-Malet, M., \& Weatherall, K. (2016). Comparing long-term placements for young children in care: Does placement type really matter? Children and Youth Services Review, 69, 56-66.

McSherry, D., Fargas-Malet, M., \& Weatherall, K. (2013). Comparing long-term placements for young children in care: The Care Pathways and Outcomes Study - Northern Ireland. London: British Association for Adoption and Fostering.

McSherry, D., Weatherall, K., Larkin, E., Malet, M. F., \& Kelly, G. (2010). Who goes where?: Young children's pathways through care in Northern Ireland. Adoption \& Fostering, 34(2), 23-37.

Moran, L., McGregor, C., \& Devaney, C. (2019). Exploring the multi-dimensionality of permanence and stability: Emotions, experiences and temporality in young people's discourses about long-term foster care in Ireland. Qualitative Social Work, 19(5-6), 1111-1129.

Morgan, D. (2011). Locating "family practices". Sociological Research Online, 16(4), 174-182.

Parker, S., \& Mayock, P. (2019). "They're always complicated but that's the meaning of family in my eyes": Homeless youth making sense of "family" and family relationships. Journal of Family Issues, 40(4), 540-570.

Sanghera, B., Ablezova, M., \& Botoeva, A. (2012). Attachment, emotions and kinship caregiving: An investigation into separation distress and family relatedness in post-Soviet Kyrgyzstani households. Families, Relationships and Societies, 1(3), 379-396.

Schachter, S., \& Singer, J. (1962). Cognitive, social and physiological determinants of emotional state. Psychological Review, 69(5), 379-399.

Sinclair, I., Baker, C., Lee, J., \& Gibbs, I. (2007). The pursuit of permanence: A study of the English child care system. Jessica Kingsley.

Skoglund, J., Thørnblad, R., \& Holtan, A. (2019). Children's relationships with birth parents in childhood and adulthood: A qualitative longitudinal study of kinship care. Qualitative Social Work, 18(6), 944-964.

Svašek, M. (2008). Who cares? Families and feelings in movement. Journal of Intercultural Studies, 29(3), 213-230.

Turner, J. H. (2007). Human emotions: A sociological theory. Routledge.

Welch, V. (2018). Talking back to "family", "family troubles", and "the looked-after child". Sociological Research Online, 23(1), 197-218.

Wilson, S., Cunningham-Burley, S., Bancroft, A., \& Backett-Milburn, K. (2012). The consequences of love: Young people and family practices in difficult circumstances. The Sociological Review, 60(1), 110-128.

Wrobel, G. M., \& Grotevant, H. D. (2019). Minding the (information) gap: What do emerging adult adoptees want to know about their birth parents? Adoption Quarterly, 22(1), 29-52. 